\title{
Alteration of sex-related developmental modules: A case of "feminized" male wing morphology in Creobroter gemmatus (Mantodea: Hymenopodidae)
}

\author{
OLIVIER BÉTHOUX
}

\begin{abstract}
Freiberg University of Mining and Technology, Institute of Geology, Department of Palaeontology, Bernhard-von-Cotta Str. 2, D-09596 Freiberg, Germany; e-mail: obethoux@yahoo.fr
\end{abstract}

Key words. Homology, modular organization, mixed gynandromorphism, feminization, evolution, Hymenopodidae

\begin{abstract}
A particular case of the alteration of the organization of a developmental module is presented, viz. mixed gynandromorphism in Creobroter gemmatus, in which a male exhibits the usual fore- and hind wing venation and shape of its sex, but patterns of coloration typical of females. Homologies between corresponding areas of the fore- and hind wings are suggested. "Feminization" is defined as the occurrence of traits typical of the female phenotype in a male, and is suggested as a plausible way in which insect wing morphology may be transformed.
\end{abstract}

\section{INTRODUCTION}

Alteration of the organization of developmental modules is currently regarded as one of the major potential sources of phenotypic, behavioural and morpho-functional novelties, acting at various hierarchical levels of organization (Patthy, 2003; Schlosser, 2004; Schlosser \& Wagner, 2004a; Love \& Raff, 2006; Rosin \& Kramer, 2009; among others). Resulting variant morphologies can become fixed at the population level, or even prompt an instantaneous speciation event ["hopeful monsters" sensu Bateman \& DiMichele (2002), viz. variant individuals are not recognized as conspecific by parents and siblings]. Such alterations have a high potential for triggering morphological radiation, i.e. become innovations of major evolutionary importance.

In addition to investigating the underlying genetic determinism, morphological comparative analyses may provide a means of delimiting modules thanks to the occurrence of "dissociability events", i.e. individuals showing a mix of module-based morphological features. Mixed gynandromorphism, in which individuals exhibiting both male and female phenotypic features without clear axial distinction, but having a clearly determined sex, is a particular case of the alteration of the organization of one or several developmental modules (axis-related gynandromorphism, such as bilateral gynandromorphism, is not considered as mixed gynandromorphism, because male and female modules are distinctly expressed in different parts of the body). Mixed gynandromorphs are reported in many insect groups, such as stick-insects (e.g. Brock, 2001) and crickets (Zuk et al., 2006).

Below I present a case of unusual wing morphology in a praying mantid, Creobroter gemmatus (Stoll, 1813). The individual is a male that exhibits the wing venation pattern and shape of a male, but wing coloration traits typical of a female, qualifying it as a mixed gynandromorph.

\section{MATERIAL AND METHODS}

Dry and determined specimens were obtained from a dealer. According to the data provided, they were collected from populations at Mt. Argopuro, East Java, Indonesia, in January 2006. Specimens were softened with ethanol after which the wings were cut off and mounted on slides in Euparal medium. Ethanol toned down the coloration of the wings to some extent (slightly). Due to the drying out of the mounting medium, empty cavities developed in some places on the wings, especially vein lacunae. Veins with lacunae devoid of Euparal appear darker in the photographs. All specimens are in my personal collection.

Photographs were taken with a Canon EOS 450D coupled to a MPE-65 mm Canon macro lens, respectively. Transmitted light was obtained from a VisiLED ACT Basis. Image processing follows that described by Béthoux \& Wieland (2009). In order to avoid censure I follow the Linnaean nomenclatural procedure but without approving it.

In the more derived mantodeans a fold crosses the anal veins in the forewings (compare Fig. 6 to Figs $7-18$ in Béthoux \& Wieland, 2009). Areas anterior and posterior to this fold will be conventionally referred to as "remigium" and "vannus", respectively (see areas delimited in Fig. 1A). On the hind wings, areas anterior and posterior to the fold located between AA1 and other anal veins will be referred to as "remigium" and "vannus", respectively (see areas delimited in Fig. 1A).

\section{COMPARATIVE ANALYSIS}

The usual wing morphology of females of C. gemmatus is reproduced in Fig. 1A. Forewing remigium is green, with a central eye-like area (brown, yellow and white) and proximal yellow area, which appears dark when viewed with transmitted light. Cross-venation is dense, with more than four rows of cells in most areas. Forewing vannus is pink proximally and dark brown distally. Hind wing remigium is dark pink, with a clear apex, while the remigium is pink proximally and dark brown distally. Dark pink and dark brown areas partly overlap. In the dark brown area cross-veins are surrounded by clear areas. Twenty female specimens were examined and all exhibited this morphology.

The usual wing morphology of males of C. gemmatus is reproduced in Fig. 1B. Compared to female forewings, those of males are longer and have a less dense network of cross-veins (the later feature varies). Forewing remigium is devoid of the proximal yellow area occurring in females. Forewing vannus is light pink. On the hind wing there is a light pink proximal area and the distal area is not distinctively coloured. Nineteen of the male specimens examined had this morphology. 

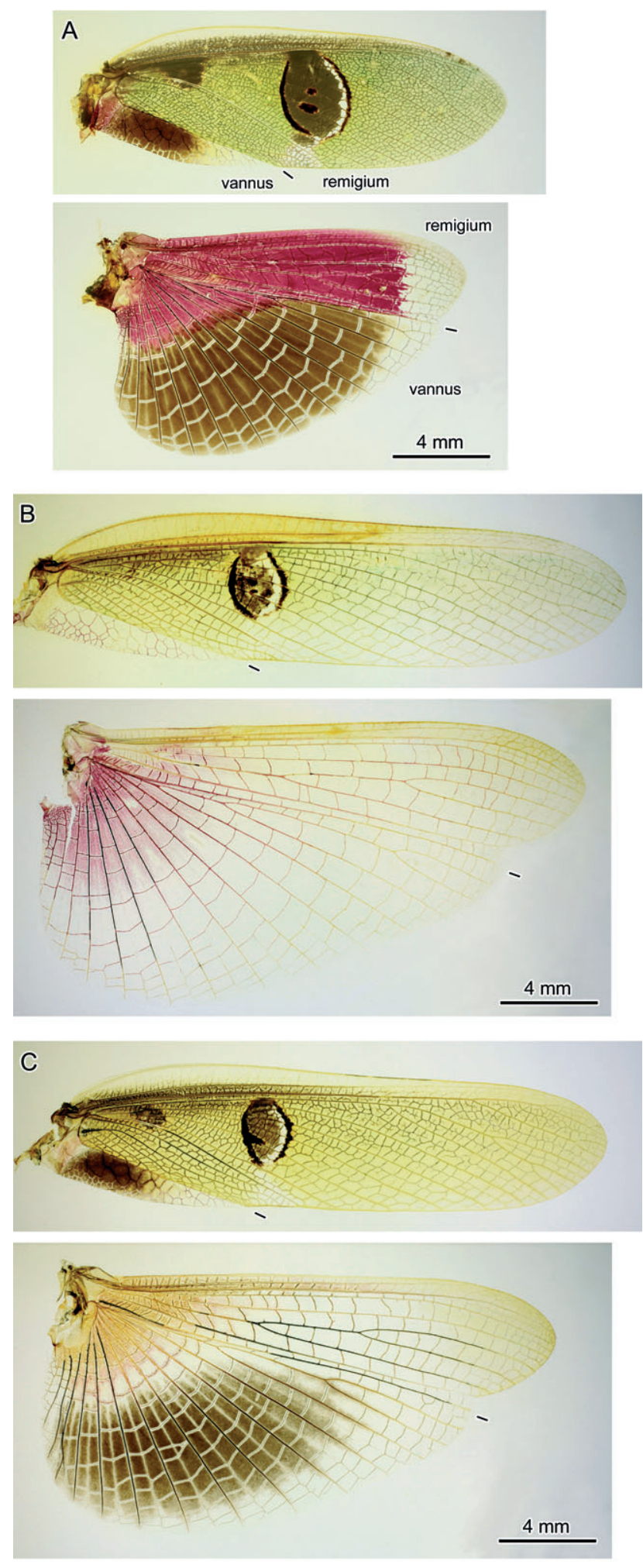

Fig. 1. Creobroter gemmatus (Stoll, 1813) (wings viewed using transmitted light; dashes delimit remigium and vannus). A - specimen IWC OB 131 ( + ), left forewing and hind wing; B specimen IWC OB 125 ( $\left.\sigma^{\star}\right)$, right forewing and hind wing; C Specimen IWC OB 128 (ठే), right forewing and hind wing.

According to the external morphology of its genitalia, the specimen whose left wings are pictured in Fig. 1C is a male (K.-D. Klass, pers. com., 2009). The shape and cross-venation of both forewings conform to that of the usual male morphology. However, there is a yellow proximal area on the forewing remigium and the vannus has a dark brown area. On both hind wings, the remigium and vannus are similar to that of other males, in that the extent of the pink area is limited to the proximal part and is paler, but the vannus has a dark brown distal area, a feature typical of females. Only one of the 20 males examined had this morphology.

\section{DISCUSSION}

The specimen IWC OB 128 is a male that exhibits the typical pattern of venation and wing shape of a male coupled with some wing coloration features of a female: the occurrence of a dark brown area on the fore- and hind wing vannuses is a typical feature of C. gemmatus females. I propose to refer to this transformation as "feminization". Feminized phenotypes could be the result of the repression of a part of the male genotype, or the expression of a part of the female genotype. The case reported by Zuk et al. (2006), in which males of Teleogryllus oceanicus (Le Guillou, 1841) (Orthoptera: Ensifera: Gryllidae) lack a number of derived structures involved in sound production typical of males, i.e. exhibiting female-like forewings, belongs to the former process, because females exhibit a plesiomorphic forewing morphology (Sharov, 1968). The process underlying the feminization of specimen IWC OB 128 is unknown.

The most parsimonious interpretation is that both fore- and hind wing vannuses of specimen IWC OB 128 have been affected by a unique alteration. Such an alteration could be of modular origin, as it occurred independently of other factors (sex in this case) and affected similar areas of different organs (Schlosser \& Wagner, 2004b). Comparison with T. oceanicus is relevant, as an alteration at a single locus results in the suppression of a set of structures involved in song production (Tinghitella, 2008), which possibly constitute a single module. Interestingly the hind wing remigium of specimen IWC OB 128 is not altered: it is devoid of the dark pink coloration typical of females. Thus it is likely that folds delimiting the remigium and vannus, as outlined above, might be homologous in both pairs of wings.

Specimen IWC OB 128 is not a spectacular case of gynandromorphism. Although it is not possible to determine whether it was fertile, or if conspecific females would have identified it as a potential mate (to my knowledge wings are not used in male courtship display in Mantodea; and F. Wieland, pers. com., 2009), it is plausible that such a discreet alteration would not have jeopardized the individual's reproductive success. It is also not implausible to assume that feminized conditions could spread and become fixed in a population.

\section{CONCLUSION}

Correlated features occurring in variants can facilitate the delimitation of the modules underlying observed morphologies. In turn, knowledge of plausible morphological transformations possibly caused by the alteration of module combinations is essential for establishing conjectures about primary homology prior to testing for congruence between characters (hence assess homology at a secondary level). Since this initial step is fundamental for phylogenetic analyses and a basis of evolutionary biology, the documentation of unusual morphologies is not a trivial pursuit. The case presented herein demonstrates that, in insects, male wing morphology could be the result of the integration of female traits.

ACKNOWLEDGMENTS. The author is a postdoctoral research fellow at the Alexander von Humboldt Foundation. I thank two anonymous reviewers for their useful comments. 


\section{REFERENCES}

Bateman R.M. \& DiMichele W.A. 2002: Generating and filtering major phenotypic novelties: neoGoldschmidtian saltation revisited. In Cronk Q.C.B., Bateman R.M. \& Hawkins J.A. (eds): Developmental Genetics and Plant Evolution. Taylor \& Francis, London, pp. 109-159.

Béthoux O. \& Wieland F. 2009: Evidence for Carboniferous origin of the order Mantodea (Insecta: Dictyoptera) gained from forewing morphology. Zool. J. Linn. Soc. 156: 79-113.

Brock P.D. 2001: Studies on the Australasian stick-insect genus Extatosoma Gray (Phasmida: Phasmatidae: Tropoderinae: Extatosomatini). J. Orthopt. Res. 10: 303-313.

Love A.C. \& RAFF R.A. 2006: Larval ectoderm, organizational homology, and the origins of evolutionary novelties. J. Exp. Zool. (B) 306: 18-34.

Patтhy L. 2003: Modular assembly of genes and the evolution of new functions. Genetica 118: 217-231.

Rosin F.M. \& Kramer E.M. 2009: Old dogs, new tricks: regulatory evolution in conserved genetic modules leads to novel morphologies in plants. Dev. Biol. 332: 25-35.

Schlosser G. 2004: The role of modules in development and evolution. In Schlosser G. \& Wagner G.P. (eds): Modularity in Development and Evolution. The University of Chicago Press, Chicago, pp. 519-582.

Schlosser G. \& Wagner G.P. (eds) 2004a: Modularity in Development and Evolution. The University of Chicago Press, Chicago, $600 \mathrm{pp}$.

Schlosser G. \& Wagner G.P. 2004b: Introduction: the modularity concept in developmental and evolutionary biology. In Schlosser G. \& Wagner G.P. (eds): Modularity in Development and Evolution. The University of Chicago Press, Chicago, pp. 1-11.

Sharov A.G. 1968: Filogeniya orthopteroidnykh nasekomykh. Trudy Paleontol. Inst. Akad. Nauk SSSR 118: 1-216.

TINGHITELLA R.M. 2008: Rapid evolutionary change in a sexual signal: genetic control of the mutation "flatwing" that renders male field crickets (Teleogryllus oceanicus) mute. Heredity 100: 261-267.

Zuk M., Rotenberry J.T. \& Tinghitella R.M. 2006: Silent night: adaptative disapperance of a sexual signal in a paratized population of field crickets. Biol. Lett. 2006: 521-524.

Received August 5, 2009; revised and accepted October 6, 2009 